\title{
Tumorous Conditions of the Hand: A Retrospective Review of 402 Cases
}

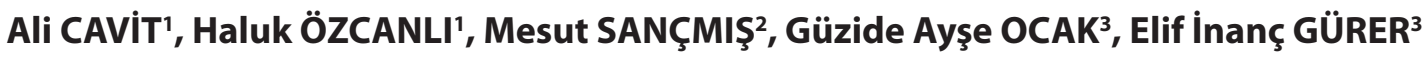

Department of Orthopaedics \& Traumatology, 'Akdeniz University Faculty of Medicine, ANTALYA, TURKEY, ${ }^{2}$ Manavgat State Hospital ANTALYA, TURKEY ${ }^{3}$ Department of Pathology, Akdeniz University Faculty of Medicine, ANTALYA, TURKEY

\begin{abstract}
Objective: Knowledge concerning treatment and care of hand lesions is often based on small case series, case reports and a few large general case series. The aim of this study is to present our experience with hand tumors' and tumor-like lesions' incidence, age range and localizations.

Material and Method: Between 2006-2016, 402 patients operated and histopathologically diagnosed with bone and soft tissue tumorous conditions of the hand were evaluated retrospectively.

Results: Three hundred sixty one out of 402 cases (89.8\%) were soft tissue tumors and 41 cases (10.2\%) were osseous tumors of the hand. A total of 10 malignant tumors (2.5\%) were encountered in the hand. The average age of the patients was 41.9 years (ranged from 1 to 83 years). Among 361 soft tissue tumors, only 6 cases $(1.6 \%)$ were malignant and they were squamous cell tumors $(n=5)$ and synovial sarcoma ( $n=1)$. The most common soft tissue pathology was ganglion cyst $(\mathrm{n}=125)$. The most common bone tumor was enchondroma, diagnosed in 26 patients $(6.4 \%$ of all patients). Primary malignant bone tumors were extremely rare in the hand; one osteosarcoma and one chondrosarcoma were reported. Metastatic tumors to the hand were seen in two patients; and they were lung carcinoma and chondrosarcoma metastasis.
\end{abstract}

Conclusion: Up-date knowledge and a thorough understanding of the nature and demographic characteristics of the tumorous conditions of the hand are crucial for accurate diagnosis and appropriate treatment.

Key Words: Hand, Neoplasms, Bone, Soft tissue, Metastasis

\section{INTRODUCTION}

Tumorous conditions of the hand are frequently encountered by hand surgeons throughout their career. Because of the conspicuous nature of the hand, a larger variety of abnormalities and variations become apparent. The presence of an enlarging mass lesion is the most frequent presenting complaint. Undescribable, localised pain can sometimes be the only symptom. Most of the tumorous conditions can be diagnosed by thorough history and physical examination, but the establishment of a definitive diagnosis is completed through biopsy (1). Early diagnosis and initiation of treatment is important to realize the aim of preservation of hand function. Clinicians should be familiar with the frequency, distribution and clinical characteristics of hand tumors and tumor-like lesions as they differ from those seen elsewhere in the body. Thus a thorough working knowledge of benign and malignant diseases affecting the hand is necessary (1). Knowledge concerning treatment and care of hand lesions is often based on small case series, case reports and a few large general case series (2). The aim of this study is to present

(Turk Patoloji Derg 2018, 34:66-72)

Received : 12.04.2017 Accepted : 20.07.2017 our experience with hand tumors' and tumor-like lesions' incidence, age range and localizations.

\section{MATERIAL and METHODS}

A total of 402 patients operated and histopathologically diagnosed with bone and soft tissue tumorous conditions of the hand between 2006-2016 were evaluated retrospectively. Approval from the ethics committee was obtained. The average age of the patients was 41.9 years (range 1 to 83 years). Analysed data of the patients were sex, age, clinical presentation, radiological investigations, localization of the tumor and histopathological features.

The biopsy procedures were undertaken by either excisional biopsy, in which the whole lump or suspicious area is removed, or incisional biopsy, in which only a sample of tissue is removed with preservation of the histological architecture of the tissue's cells (3). All lesions were treated surgically. Patients with malignant or metastatic tumors underwent full metastatic workup, including laboratory studies, chest radiography, computed tomography of the abdomen, chest and pelvis, and MRI for the sarcomas. 


\section{RESULTS}

Three hundred sixty one out of 402 cases (89.8\%) were soft tissue tumors while 41 cases (10.2\%) were osseous tumors of the hand. A total of 10 malignant tumors (2.5\%) were encountered in the hand; 4 of them were osseous and 6 were of soft tissue origin. Two hundred sixteen patients (53.7\%) were female and $186(46.3 \%)$ were male. The average age of the patients was 41.9 years (range 1 to 83 years). A mass growth and pain were the major complaints of the patients. Demographic data of all patients with soft tissue tumors and tumor-like lesions and localizations are presented in Table I and Table II, respectively. Among the 361 soft tissue tumors, only 6 cases (1.6\%) were malignant and they were squamous cell tumors $(n=5)$ and synovial sarcoma $(n=1)$.

The most common soft tissue pathology was ganglion cyst (GC) $(\mathrm{n}=125)$. Female predominance was seen in ganglion cysts ( $\mathrm{n}=71,56.8 \%)$. Among all lesions, 64 cases occurred in the left hand, 61 in the right hand. The majority of the lesions were located in the wrist $(n=86,68.8 \%)$, and the majority of the wrist location was the dorsal side $(n=49)$. The distribution of the other locations of the lesions were the dorsum of the hand, palm, and the 1st, $2 \mathrm{nd}, 3 \mathrm{rd}, 4 \mathrm{th}$ and 5 th fingers at $13.7 \%, 1.6 \%, 3.2 \%, 2.5 \%, 6.5 \%, 3.2 \%$ and
$0.8 \%$ respectively. All lesions were treated surgically. Giant cell tumor of tendon sheath (GCTTS) accounted for $22.1 \%$ of all soft tissue tumors as the second most common tumor $(\mathrm{n}=80)$ (Figure 1A-D). The index finger was the most common site for GCTTS with 27 cases (33.75\%). Only one case developed recurrence during the follow-up period.

Forty one cases $(10.2 \%)$ were diagnosed as hemangioma. The distribution of the types of the hemangiomas were lobular capillary hemangioma (pyogenic granuloma) in 21 cases, cavernous hemangioma in 10 cases, capillary hemangioma in 7 cases, intramuscular hemangioma in one case, Masson's hemangioma in one case and hobnail hemangioma in one case. Another tumor of vascular origin, glomus tumors were found in 18 patients. The main clinical presentation was pain. Other soft tissue tumors and tumor-like lesions are listed in Table I.

A total of 41 patients (10.2\%) were diagnosed with osseous tumors of the hand (Table III). The majority of bone tumors were benign $(n=37,90.2 \%)$. The most common bone tumor was enchondroma, diagnosed in 26 patients (6.4\% of all patients). Thirteen patients (50\%) were female and 13 patients (50\%) were male with a mean age of 32.7 years (range 6 to 61 years). The location of the tumors were

Table I: Soft tissue tumors

\begin{tabular}{lcccc}
\hline \multicolumn{1}{c}{ Tumor } & Number of & \multicolumn{2}{c}{ Age } & Gender \\
\cline { 3 - 5 } & Patients & Range & Mean & $(\mathbf{F} / \mathbf{M})$ \\
\hline Ganglion cyst & 125 & $3-83$ & 41.4 & $71 / 54$ \\
\hline Giant cell tumor of tendon sheath & 80 & $10-78$ & 44.2 & $53 / 27$ \\
\hline Hemangioma & 41 & $8-62$ & 38.2 & $24 / 17$ \\
\hline Lipoma & 20 & $23-83$ & 51.3 & $12 / 8$ \\
\hline Glomus tumor & 18 & $28-71$ & 48.1 & $11 / 7$ \\
\hline Schwannoma & 10 & $26-77$ & 54.9 & $6 / 4$ \\
\hline Epidermal cyst & 20 & $13-75$ & 39.6 & $3 / 17$ \\
\hline Palmar fibromatosis & 17 & $9-74$ & 52.4 & $4 / 13$ \\
\hline Fibroma & 7 & $13-60$ & 38.4 & $2 / 5$ \\
\hline Lipoblastoma & 2 & $1-7$ & 4 & $1 / 1$ \\
\hline Traumatic neuroma & 5 & $7-33$ & 23.8 & $1 / 4$ \\
\hline Papillary endothelial hyperplasia & 3 & $15-62$ & 38 & $3 / 0$ \\
\hline Granular cell tumor & 1 & - & 32 & $0 / 1$ \\
\hline Extraskeletal chondroma & 1 & - & 26 & $1 / 0$ \\
\hline Angiolymphoid hyperplasia & 1 & - & 53 & $1 / 0$ \\
\hline Fibroepithelial polyp & 2 & $35-45$ & 40 & $2 / 0$ \\
\hline Cutaneous leiomyoma & 1 & - & 4 & $1 / 0$ \\
\hline Synovial chondromatosis & 1 & - & 65 & $0 / 1$ \\
\hline Squamous cell carcinoma & 5 & $45-71$ & 58.8 & $1 / 4$ \\
\hline Synovial sarcoma & 1 & - & 36 & $0 / 1$ \\
\hline
\end{tabular}


as follows: proximal phalanx in 13 cases, middle phalanx in 5 cases, distal phalanx in 5 cases, and the metacarpal bones in 2 cases. The ring finger was the most common site for enchondromas $(n=8,30.7 \%)$. Surgical treatment with curettage and bone grafting was performed in all patients. Other benign osseous tumors reported in this study were aneurysmal bone cyts $(n=2)$, osteoid osteomas $(n=4)$, giant cell tumors of the bone $(n=2)$, osteochondroma $(n=1)$ and giant cell reparative granuloma $(n=2)$. Os capitatum, hamatum, trapezoideum and the proximal phalanx of the middle finger were the locations of osteoid osteoma. Localizations of all osseous tumors are presented in Table IV. Primary malignant bone tumors were extremely rare in the hand; one osteosarcoma and one chondrosarcoma were reported. Tumors metastatic to the hand were seen in two patients and they were lung carcinoma and chondrosarcoma metastasis (Figure 2 A-D).
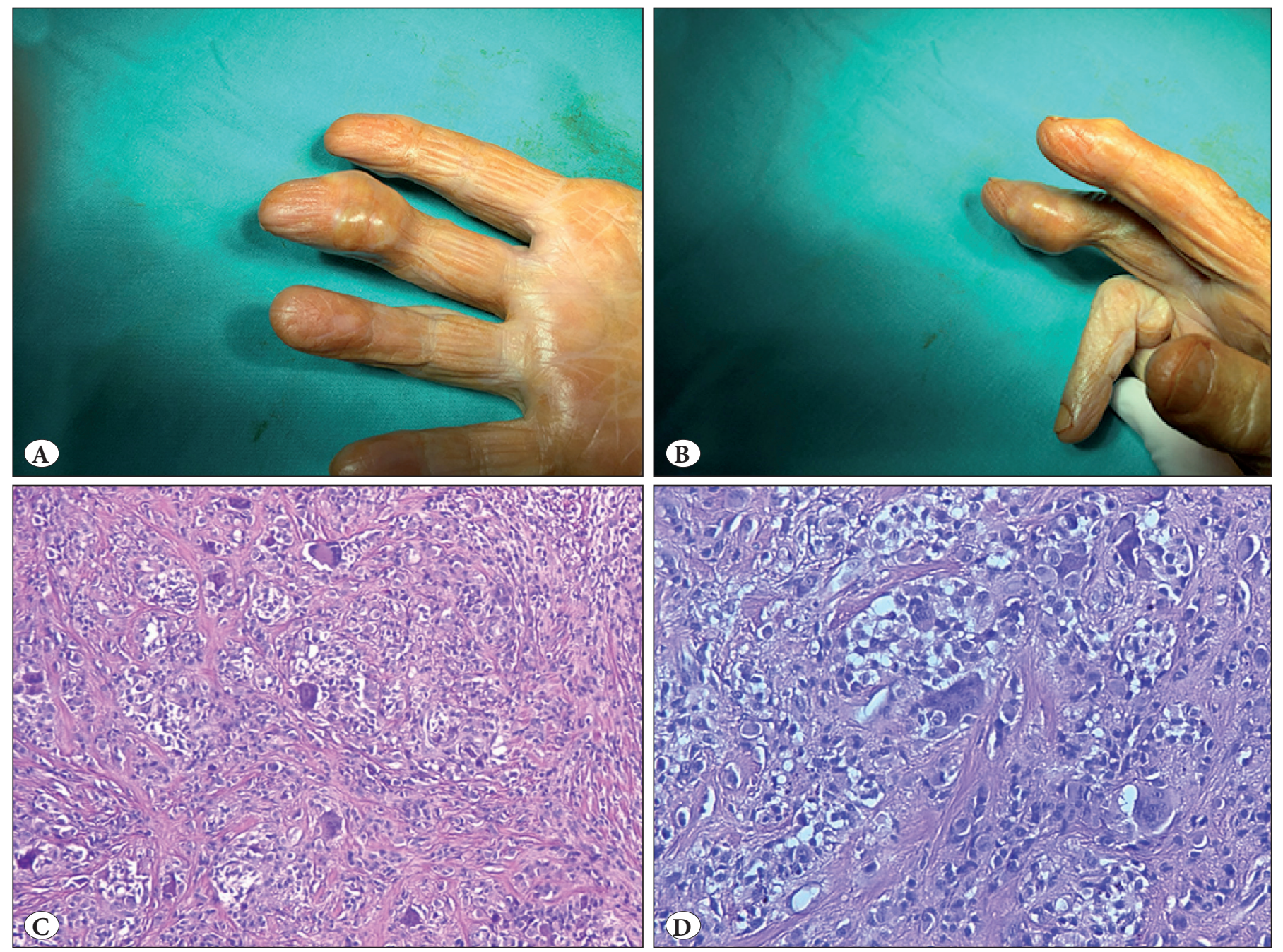

Figure 1: A,B) Pre-operative view of the GCTTS of the third finger. C,D) Microscopic view showing GCTTS. Small, histiocyte-like, rounded or polygonal mononuclear cells and larger epithelioid mononuclear cells with varying numbers of osteoclast-like giant cells (H\&E; $\mathrm{x} 200$ and $\mathrm{x} 400)$. 
In Campanacci's series of patients with hand tumors and tumor like lesions, benign ones accounted for $89.8 \%$ and malignant tumors for $10.2 \%$ (7). These incidences were similar in Dahlin's series; out of 194 hand tumors, $86.6 \%$ of the patients had benign lesions (8). In this study including 402 patients with hand tumors and tumor like lesions, patients with benign lesions accounted for 97.5\% ( $\mathrm{n}=392)$ and malignant tumors for $2.5 \%(\mathrm{n}=10)$. Nonagressive, benign neoplasms are usually treated with simple surgical excision. Although the majority of the lesions are benign, malignancy should always be suspected with rapid growth and rapid change in the characteristics of the lesions.

Ganglion cysts (GC) are the most frequently encountered masses of the hand and wrist, affecting women more commonly than men $(9,10)$. Ganglions generally (70\%) occur between the second and fourth decade of life (2).

Table II: Localizations of soft tissue tumors

\begin{tabular}{|c|c|c|c|c|c|c|c|c|c|}
\hline \multirow{2}{*}{ Tumor } & \multicolumn{5}{|c|}{ Fingers } & \multicolumn{2}{|c|}{ Hand } & \multirow{2}{*}{ Wrist } & \multirow{2}{*}{ Tota } \\
\hline & 1st & 2nd & 3rd & 4th & 5th & Palm & Dorsum & & \\
\hline Ganglion cyst & 4 & 3 & 8 & 4 & 1 & 2 & 17 & 86 & 125 \\
\hline Giant cell tumor of tendon sheath & 15 & 27 & 16 & 6 & 7 & 3 & 3 & 3 & 80 \\
\hline Hemangioma & 4 & 6 & 7 & 3 & 3 & 13 & - & 5 & 41 \\
\hline Lipoma & 1 & 3 & 2 & 2 & 2 & 8 & 2 & - & 20 \\
\hline Glomus tumor & 5 & 3 & 2 & 5 & 1 & 1 & - & 1 & 18 \\
\hline Schwannoma & - & 1 & - & 1 & - & 5 & - & 3 & 10 \\
\hline Epidermal cyst & 6 & 7 & - & 2 & 1 & 4 & - & - & 20 \\
\hline Palmar fibromatosis & 2 & 1 & 3 & 5 & 6 & - & - & - & 17 \\
\hline Fibroma & - & 3 & 1 & - & 1 & 2 & - & - & 7 \\
\hline Lipoblastoma & - & - & - & - & - & 1 & 1 & - & 2 \\
\hline Traumatic neuroma & - & - & 2 & - & - & - & - & 3 & 5 \\
\hline Papillary endothelial hyperplasia & - & - & 1 & - & - & 2 & - & - & 3 \\
\hline Granular cell tumor & - & 1 & - & - & - & - & - & - & 1 \\
\hline Extraskeletal chondroma & - & - & - & 1 & - & - & - & - & 1 \\
\hline Angiolymphoid hyperplasia & - & - & - & - & - & 1 & - & - & 1 \\
\hline Fibroepithelial polyp & - & 1 & - & - & 1 & - & - & - & 2 \\
\hline Cutaneous leiomyoma & - & - & - & - & - & - & - & 1 & 1 \\
\hline Synovial chondromatosis & - & - & - & - & - & - & - & 1 & 1 \\
\hline Squamous cell carcinoma & 2 & 2 & 1 & - & - & - & - & - & 5 \\
\hline Synovial sarcoma & - & - & - & - & - & - & 1 & - & 1 \\
\hline
\end{tabular}

Table III: Bone tumors

\begin{tabular}{lcccc}
\hline \multirow{2}{*}{ Tumor } & Number of & \multicolumn{2}{c}{ Age } & Gender \\
\cline { 3 - 5 } & patients & Range & Mean & $(\mathbf{F} / \mathbf{M})$ \\
\hline Enchondroma & 26 & $6-61$ & 32.7 & $13 / 13$ \\
\hline Osteoid osteoma & 4 & $20-35$ & 27.7 & $1 / 3$ \\
\hline Aneurysmal bone cyst & 2 & $12-32$ & 22 & $1 / 1$ \\
\hline Giant cell tumor of bone & 2 & $38-54$ & 46 & $2 / 0$ \\
\hline Giant cell reparative granuloma & 2 & $18-54$ & 36 & $1 / 1$ \\
\hline Osteochondroma & 1 & - & 17 & $1 / 0$ \\
\hline Osteosarcoma & 1 & - & 28 & $0 / 1$ \\
\hline Chondrosarcoma & 1 & - & 43 & $0 / 1$ \\
\hline Lung carcinoma metastasis & 1 & - & 43 & $0 / 1$ \\
\hline Chondrosarcoma metastasis & 1 & - & 47 & $0 / 1$ \\
\hline
\end{tabular}


Table IV: Localizations of bone tumors

\begin{tabular}{|c|c|c|c|c|c|c|c|c|}
\hline \multirow{2}{*}{ Tumor } & \multicolumn{5}{|c|}{ Fingers } & \multirow{2}{*}{$\begin{array}{c}\text { Hand } \\
\text { Metacarpal bone }\end{array}$} & \multirow{2}{*}{ Wrist } & \multirow{2}{*}{ Tota } \\
\hline & 1st & 2nd & 3rd & 4th & 5 th & & & \\
\hline Enchondroma & 1 & 6 & 3 & 7 & 6 & 2 & 1 (distal ulna) & 26 \\
\hline Osteoid osteoma & - & - & 1 & - & - & - & 3 & 4 \\
\hline Aneurysmal bone cyst & - & - & 1 & - & - & 1 & - & 2 \\
\hline Giant cell tumor of bone & - & - & - & - & - & 2 & - & 2 \\
\hline Giant cell reparative granuloma & - & - & 1 & 1 & - & - & - & 2 \\
\hline Osteochondroma & 1 & - & - & - & - & - & - & 1 \\
\hline Osteosarcoma & - & - & 1 & - & - & - & - & 1 \\
\hline Chondrosarcoma & - & - & - & - & - & 1 & - & 1 \\
\hline Lung carcinoma metastasis & 1 & - & - & - & - & - & - & 1 \\
\hline Chondrosarcoma metastasis & - & - & - & - & - & 1 & - & 1 \\
\hline
\end{tabular}
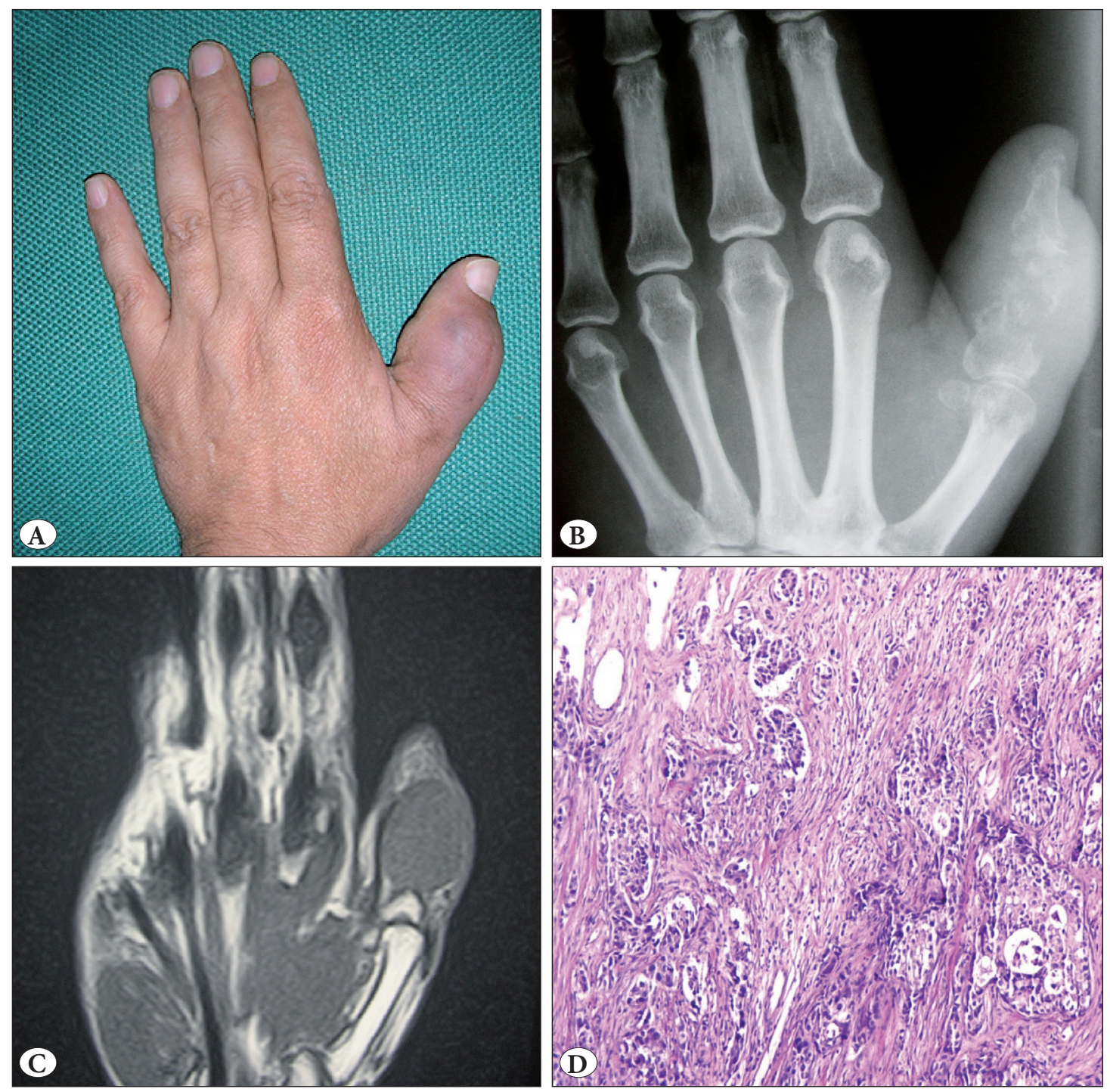

Figure 2: A) Lung carcinoma metastasis to the left thumb. B) X-ray of lung carcinoma metastasis; destructive osteolytic lesion in proximal phalanx. C) Coronal image of the lesion on MRI. D) Metastatic carcinoma in the soft tissue as irregular adenoid structures and solid communities (H\&E; x 200). 
Clinically, ganglions usually occur singly, and there are four typical locations at which GCs are most likely to arise; dorsum of the wrist, volar wrist, dorsal distal interphalangeal joint and volar metacarpophalangeal joint (10). In a series of 134 hand masses, $27 \%$ of cases were diagnosed as GC (11). In the present study, GC was the most frequent pathology encountered in the hand, including 125 out of 402 patients with bone and soft tissue tumors of the hand (31\%). Our findings are also consistent with the literature as the majority of the ganglion cysts were seen in females and between the second and fourth decade. GCs do not pose a risk for malignant degeneration, and conservative management with observation or splinting is initially recommended. Other nonoperative treatments such as aspiration, closed rupture or injection of hyaluronidase or sclerosing solutions have higher recurrence rates (10). Surgery should be considered in the presence of a consistent symptomatic cyst, limitation of movement and nerve palsies. If a stalk is visualized during the excision of a ganglion cyst by either open surgery or arthroscopically, it should be completely removed to prevent recurrence $(3,10)$. Recurrence has been reported to be as high as $40 \%$ following incomplete removal (12).

Giant cell tumor of the tendon sheath (GCTTS), also known as fibrous xanthoma or pigmented villonodular tenosynovitis, is a benign soft tissue tumor which is the second most common tumor seen in the hand (2). GCTTS mostly occurs in the third to fourth decade, with a female predominance (2/1) (13). Our results were correlated with the literature; GCTTS was the second most common tumor with $22.1 \%$ of all bone and soft tissue tumors $(\mathrm{n}=80)$. There was female predominance (1.9/1) with a mean age of 44.2 . In their study on 191 patients, Saglık et al. reported GCTTS to be the most common soft tissue tumor; however patients with extraosseous ganglion cyts were not included (14). Volar surfaces of the radial three digits are typical locations for GCTTS $(2,16)$. The index finger was the most common site in our study. Marginal excision is the recommended treatment, although the reported risk of recurrence is from 0 to 44 percent $(15,16)$. High recurrence rates are associated with poor encapsulation, satellite lesions, concurrent degenerative joint disease, intraosseous involvement, distal locations or involvement of the adjacent joint/tendon $(16,17)$.

Hemangiomas are neoplastic proliferations of the endothelium. The hand is the third most common site, involving $15 \%$ of whole body hemangiomas (18). These neoplasms arise during the first weeks of life, experience a period of growth followed by involution, and typically regress over the first 7 years of life (9-19,20). Hemangiomas do not undergo malignant degeneration and, bleeding and ulceration are uncommon in the hand $(3,21)$. Management of hemangiomas is usually conservative but medical (steroid, vincristine, interferon alfa, laser ablation) or surgical treatment should be considered when the lesions are large enough to interfere with hand function, noninvoluting, or symptomatic (ulceration, bleeding, recurrent infection) (23-9-22,23). Surgical treatment should be complete excision of the lesion, and the 5-year recurrence after excision is reported as 19\% (24). In our series, hemangiomas were the third most commonly observed soft tissue pathology and the most common type was lobular capillary hemangioma (pyogenic granuloma), seen in 21 cases.

The most common primary bone tumors arising from the hand are enchondromas $(2,3)$. Approximately $35 \%$ of all enchondromas arise in the hand and enchondromas account for 90 percent of all primary bone tumors encountered in the hand $(1,2)$. Farzan et al. assessed 99 patients with osseous hand tumors and 31 cases $(31.3 \%)$ were diagnosed as enchondromas (25). Sağlık et al. reported 59 patients with enchondroma in the hand (four within soft tissue) out of 210 patients with enchondroma located elsewhere in the body (28.09\%); enchondromas also constituted 52.3 percent of the whole bone tumors of the hand in the same study (14). In another study, enchondromas were diagnosed in 297 patients (\%47.1) out of 631 patients with primary bone tumors (26). Our findings are consistent with the literature. In this study, 26 cases (63.4 percent of all bone tumors) were diagnosed as enchondroma.

Soft tissue sarcomas are relatively rare in the hand. Various soft tissue sarcomas of the hand exist and the most common ones are synovial and epithelioid sarcomas $(2,27)$. Rhabdomyosarcoma is most frequently seen in childhood and alveolar rhabdomyosarcoma is the most common histologic variant seen in the hand (2). Sağllk et al. reported alveolar rhabdomyosarcoma as the most common malignancy in soft tissue in their study (14). There were 4 cases of squamous cell carcinoma and one case of synovial sarcoma in the present study.

Bone sarcomas are also rarely seen in the hand; however careful preoperative planning is required to ensure complete removal of the tumor. Chondrosarcoma is the most common primary malignant bone tumor occurring in the hand. These tumors are either, arising de novo, or secondary, arising from a pre-existent cartilaginous mass such as enchondroma or osteochondroma. Malignancy should be kept in mind when there are signs like rest pain, advanced patient age, bony cortical disruption, associated soft tissue mass, and permeative lytic pattern on x-ray (28). 
Osteogenic sarcoma is the most common primary bone tumor seen in children and adolescents, but it is rarely seen as a primary lesion in the hand. As Ewing's sarcoma's clinical features resemble infection, care must be taken to avoid misdiagnosis.

Metastatic tumors of the hand are extremely rare, encompassing $0.1 \%$ of all skeletal metastases. The most frequent sites of primary cancer are the lung, breast and kidney (3). There is a predilection for the distal falanx. In Campanacci's series, patients with metastasis to the hand comprised $0.5 \%$ of whole bony metastases (7). In another study of hand tumors with 191 patients, this rate was $1.4 \%$ (14). Ozcanli et al. reported three patients with hand metastasis, composed of one transitional cell carcinoma, one chondrosarcoma, and one colonic adenocarcinoma, during a 20-year period, from 1980 to 2000 (29). In the present study, we observed 2 cases of metastatic tumors of the hand among 402 patients ( $0.5 \%)$, consisting of one lung carcinoma and one chondrosarcoma metastasis.

In conclusion, up-to-date knowledge and a thorough understanding of nature and demographic characteristics of the tumorous conditions of the hand are crucial for an accurate diagnosis and appropriate treatment.

\section{CONFLICT of INTEREST}

The authors declare no conflict of interest.

\section{REFERENCES}

1. Henderson M, Neumeister MW, Bueno RA Jr. Hand tumors: II. Benign and malignant bone tumors of the hand. Plast Reconstr Surg. 2014;133:814-21.

2. Athanasian EA. Bone and soft tissue tumors. In: Wolfe SW, Hotchkiss RN, Pederson WC, Kozin SH, editors. Green's operative hand surgery. 6th ed. Philadelphia: Churchill Livingstone; 2011. 2141-97.

3. Hsu CS, Hentz VR, Yao J. Tumours of the hand. Lancet Oncol. 2007;8:157-66.

4. Garcia J, Bianchi S. Diagnostic imaging of tumors of the hand and wrist. Eur Radiol. 2001;11:1470-82.

5. Kransdorf MJ, Meis JM. From the archives of the AFIP Extraskeletal osseous and cartilaginous tumors of the extremities. Radiographics. 1993;13:853-84.

6. Khaled W, Drape JL. MRI of wrist and hand masses. Diagn Interv Imaging. 2015;96:1238-46.

7. Campanacci M. Bone and soft tissue tumors: Clinical features, imaging, pathology, and treatment. Wein: Springer-Verlag; 1999.

8. Unni KK. Dahlin's bone tumors. General aspects and data on 11087 cases. 5th ed. Philadelphia: Lippincott-Raven; 1996.

9. Henderson M, Neumeister MW, Bueno RA Jr. Hand tumors: I. Skin and Soft-tissue tumors of the hand. Plast Reconstr Surg. 2014;133:154-64.
10. Nahra ME, Bucchieri JS. Ganglion cysts and other tumor related conditions of the hand and wrist. Hand Clin. 2004;20:249-60.

11. Capelastegui A, Astigarraga E, Fernandez-Canton G, Saralegul I, Larena JA, Merino A. Masses and pseudomasses of the hand and wrist: MR findings in 134 cases. Skeletal Radiol. 1999;28:498-507.

12. Thornburg LE. Ganglions of the hand and wrist. J Am Acad Orthop Surg. 1999;7:231-38.

13. De Schepper AM, Bloem JL. Soft tissue tumors: Grading, staging, and tissue-specific diagnosis. Top Magn Reson Imaging. 2007;18:431-44.

14. Sağlık Y, Atalar H, Armangil M, Başarır K, Yıldız Y, Bilgin S. Management of tumors and tumor-like lesions of the hand: A review of 191 patients. Eklem Hastalık Cerrahisi. 2013;24:149-55.

15. Adams EL, Yoder EM, Kasdan ML. Giant cell tumors of the tendon sheath: Experience with 65 cases. Eplasty. 2012;12:e50.

16. Lanzinger WD, Bindra R. Giant cell tumor of the tendon sheath. J Hand Surg Am. 2013;38:154-7.

17. Williams J, Hodari A, Janevski P, Siddiqui A. Recurrence of giant cell tumors in the hand: A prospective study. J Hand Surg Am. 2010;35:451-6.

18. Finn MC, Glowacki J, Mulliken JB. Congenital vascular lesions: Clinical application of a new classification. J Pediatr Surg. 1983;18:894-900.

19. Sobanko JF, Dagum AB, Davis IC, Kriegel DA. Soft tissue tumors of the hand: 1. Benign. Dermatol Surg. 2007;33:651-67.

20. Canavese F, Soo BC, Chia SK, Krajbich JI. Surgical outcome in patients treated for hemangioma during infancy, childhood and adolescence: A retrospective review of 44 consecutive patients. J Pediatr Orthop. 2008;28:381-6.

21. Upton J, Coombs CJ, Mulliken JB, Burrows PE, Pap S. Vascular malformations of the upper limb: A review of 270 patients. J Hand Surg Am. 1999;24:1019-35.

22. Palmieri TJ. Vascular tumors of the hand and forearm. Hand Clin. 1987;3:225-40.

23. Blei F. Vascular anomalies: From bedside to bench and back again. Curr Probl Pediatr Adolesc Health Care. 2002;32:72-93.

24. Tang P, Hornicek FJ, Gebhardt MC, Cates J, Mankin HJ. Surgical treatment of hemangiomas of soft tissue. Clin Orthop Relat Res. 2002;399:205-10.

25. Farzan M, Ahangar P, Mazoochy H, Ardakani MV. Osseous tumours of the hand: A review of 99 cases in 20 years. Arch Bone Jt Surg. 2013;1:68-73.

26. Simon MJ, Pogoda P, Hövelborn F, Krause M, Zustin J, Amling M, Barvencik F. Incidence, histopathologic analysis and distribution of tumours of the hand. BMC Musculoskelet Disord. 2014;15:182.

27. Brien EW, Terek RM, Geer RJ, Caldwell G, Brennan MF, Healey JH. Treatment of soft-tissue sarcomas of the hand. J Bone Joint Surg Am. 1995;77:564-71.

28. Ogose A, Unni KK, Swee RG, May GK, Rowland CM, Sim FH. Chondrosarcoma of small bones of the hands and feet. Cancer. 1997;80:50-9.

29. Ozcanli H, Özdemir H, Özenci AM, Soyuncu Y, Aydın AT. Metastatic tumors of the hand in three cases. Acta Orthop Traumatol Turc. 2005;39:445-8. 